\title{
On Appropriacy of Thanking: Dynamic Compensation and Adaptation
}

\author{
Baiqiu Liao ${ }^{1}$ \\ ${ }^{1}$ School of Foreign Languages, Leshan Normal University, Leshan, China \\ Correspondence: Baiqiu Liao, School of Foreign Languages, Leshan Normal University, NO.778 Binhe Road, \\ Leshan, Sichuan, China. Tel: 86-180-8063-7190. E-mail: lbqlanguage@126.com
}

Received: February 12, 2013 Accepted: March 5, 2013 Online Published: April 3, 2013

doi:10.5539/elt.v6n5p71 URL: http://dx.doi.org/10.5539/elt.v6n5p71

\begin{abstract}
Appropriacy is the paramount consideration of such an inherently polite speech act as thanking in its use. Traditional study of thanking focuses more on the quantitative investigation of its diverse forms and functions than on interpretation of the process in which it is used appropriately and adequately or not among English native or nonnative speakers. This paper particularly explores how to make the speech act of thanking appropriate and acceptable in dynamic context from the perspective of Chinese EFL learners who tend to respond in mute English or Chinglish in cross-culture thanking situation through analysis of the spoken discourse based on cognitive and cultural comparative approach. It contents that in foreign language learning environment, L2 contextual knowledge also comes into compensation for the lack of authentic context compatible with L2 use in the diachronic process of EFL learning as L1 contextual knowledge does. In a specific communicative situation, the learner has to manipulate his contextual cognition consciously and make an appropriate choice among linguistic or strategic forms activated by the two types of contextual knowledge stored in memory. The choice-making needs considering adaptation to dynamic context like the objects of gratitude, the benefactor's psychological state and the communicative social context as the most important parameters. Only in that way is appropriacy of thanking possible in cross-cultural communication.
\end{abstract}

Keywords: thanking, appropriacy, dynamic compensation, contextual cognition, adaptation

\section{Introduction}

English teaching in China has long attached importance to usage rather than use, accuracy rather than appropriacy. It leads to the fact that Chinese EFL learners are used to piling thousands of English words in their mind but tend to silence their speech more or less before foreigners or talk in English characterized by Chinese thinking mode, called Mute English or Chinglish respectively, both of which are hard to create a comfortable conversation and conversely give rise to pragmatic failure. As China is increasingly open to the outside world, intercultural communication becomes active and frequent. Language use like speaking and writing becomes a hot need when a growing number of average Chinese begin to go abroad to travel, learn, do business, etc. Pragmatic appropriacy is therefore increasingly highlighted in English education in China.

Thanking or expressing gratitude as a convivial speech act is frequently used in daily communication, for it is the universal ritual and convention all the peoples on the globe observe. It seems easy and simple to express gratitude even in cross-cultural communication. Hence, Chinese EFL learners tend to transfer Chinese linguistic forms and strategies of thanking into English, but unexpectedly pragmatic failure takes place at times. Thanking is of critical social value and cross-cultural disparity as well. Appropriate thanking can engender feelings of warmth and solidarity among interlocutors, and promote a successful social contact. Instead, the failure to express gratitude adequately and properly can have negative social consequences, damaging the relationship between interlocutors. Therefore, this essay attempts to explore how to make thanking appropriate and acceptable by way of dynamic compensation and adaptation guided by contextual cognition so as to improve cross-cultural communicative competence of Chinese EFL learners.

\section{Previous Studies of Thanking}

Investigation of thanking was conducted mainly in last five decades. It still has aroused an interest in investigating its use in a wide range of languages and cultures in recent years (Cheng, 2005; Johansen, 2008; Farnia \& Suleiman, 2009; Ahar \& Eslami, 2011; Pishghadam, 2011; Cui, 2012).

Theoretical study of thanking originates primarily from Speech Act Theories (Austin, 2002; Searle, 2001a, 
2001b) and Politeness Theories (Leech, 1983; Brown and Levinson, 1987) since thanking is thought of as an inherent polite speech act in pragmatics. For example, Searle (2001b, p. 67) works out four felicity conditions or constitutive rules to justify the successful performance of a speech act, as follows:

Table 1. Searle's felicity conditions for the speech act of thanking

\begin{tabular}{ll}
\hline Types of rule & Thank (for) \\
Propositional content & Past act A done by H. \\
Preparatory & A benefits S and S believes A benefits S. \\
Sincerity & S feels grateful or appreciative for A. \\
Essential & Counts as an expression of gratitude or appreciation. \\
\hline
\end{tabular}

Unlike Searle, Leech (1983, p. 125) sees the goal of thanks as the restoration of equilibrium on the cost-benefit scale since the speaker presupposes a previous transfer of goods or services from $h$ to $s$ if he or she thanks someone. Therefore, he focuses on how to minimize benefit to others and maximize cost to self through indirect speech acts.

Empirical study of thanking mainly comes from contrastive analyses. For example, Eisenstein and Bodman (1986) conducted the most comprehensive study of thanking in native and non-native speakers of English such as those from Japan, Spain, South Korea, China and Russia. They noted that thank you can be used ironically and have the illocutionary function of accepting or rejecting an offer and signaling the conclusion of the conversation, besides its usual function of expressing gratitude. Wolfson (1989) analyzed in detail the negative transfer of thanking in cross-cultural communication. He remarked that advanced learners have been found to avoid direct translation or transfer of the corresponding responses from their own first language in expressing gratitude. Their studies reveal that advanced English language learners do not necessarily express gratitude appropriately and adequately. Based on the London-Lund Corpus of Spoken English, Aijmer (1996) made a wide range of investigation of thanking in its strategies, forms, response and phonetic features, etc. Based on Searle's study, she (1996, p. 34) gave a description of the expressive speech acts with thanking included, as follows:

Factivity, i.e. the truth of the state of affairs is presupposed by the speaker to be true.

A psychological state is expressed.

The propositional content expresses some property ascribed to the speaker or the hearer.

Recent years witnessed more comparative investigation of gratitude expression among different groups of people, for instance, about the choice-making of thanking strategies between Iranian EFL learners at high and low levels of language proficiency (Farnia \& Suleiman, 2009), the effect of social status and size of imposition on the gratitude strategies between Persian and English speakers (Ahar \& Eslami, 2011), and the use of, and response to unsolicited email advertising messages between Americans and Koreans (Hee \& Lee, 2012). Those studies of thanking, to different degrees, displays the cultural disparity of expressing gratitude as a universal ritual, some prominent and some subtle, and cross-linguistic and cross-cultural influence, therefore, cannot be neglected in cross-cultural communication.

Domestically, Chinese scholars such as Bi (2009) and Du (2010) explored the disparity of expressing gratitude between Chinese and English from the perspective of cross-cultural communication. Qu \& Chen (2001) investigated the indirect speech act of thanking in Shanghai Dialect, which reveals the dialectical characteristics and differences of expressing gratitude in China. Hou (2004) proposed Dynamic Politeness-Appropriateness Interaction (DPAI) which consists of four postulates to reveal the dynamic relation between politeness and appropriateness and acceptability. According to DPAI, only if an utterance of a speaker is polite and appropriate, the utterance is acceptable or very acceptable to the hearer.

In short, previous studies of thanking at home and abroad demonstrate that they focus more on the quantitative investigation of its diverse forms and functions in a specific language or culture than on interpretation of the process in which it is appropriately and adequately used among English native or nonnative speakers, more on static contrastive analyses than on exploration of the dynamic language use, particularly with inadequate consideration of appropriacy of thanking used by Chinese EFL learners in intercultural communication. But recently, more attention is paid to the interlanguage pragmatic development for the ESL and EFL learners in terms of the study of thanking. 


\section{Thanking and Dynamic Compensation}

Thanking is universal. People in Chinese or English culture show their gratitude to those who do a favor for them. But thanking is cross-culturally different on the other hand, used more frequently and in a wider range of situations in English than in Chinese. Their linguistic forms and strategies also manifest the cultural disparity. It is the trivial differences that tend to cause pragmatic failure in its use. As for that failure, Chinese-speaking learners of English tend to use mute English or Chinglish when showing gratitude, which is elaborated in compensation hypothesis.

\subsection{Introducion to Compensation Hypothesis}

Compensation hypothesis, initiated by Wang (2003), is intended to account for L2 learning in the foreign language context. According to the hypothesis, fluent and accurate use of language presupposes that linguistic and contextual knowledge is properly welded. That is to say, only when linguistic and contextual knowledge and authentic context are well matched is the appropriate language use possible. However, the foreign language learning setting is characterized by a lack of authentic contexts compatible with L2 use. By way of compensating for this lack, L1 contextual knowledge comes in, thus activating those L1 forms which go with it and resulting in L1 transfer. The compensatory process is not simply equivalent to replacing a L2 form with a L1 form. Rather, the superficial replacement is mediated and effected by learners' L1 contextual knowledge. When compensation takes place, transfer is easy to arise, sometimes bringing about mute English or Chinglish. For example:

1) A: It's amazing. You did it.

B: ...... (no response)

C: It's just so so.

The example above reveals two Chinese students' inappropriate responses toward a foreign teacher's praising. According to the compensation hypothesis, the two responses derive from divorce or mismatch between linguistic forms and contextual knowledge. For instance, Speaker B made no response because he couldn't retrieve such an information packet in the memory that English native speakers tend to show their gratitude for praise by saying Thank you or Thanks, so that the current context failed to activate corresponding L2 forms. Speaker $\mathrm{C}$ responded in Chinglish because L1 contextual knowledge of praising-denigrating convention in Chinese culture coming in for compensation resulted in the mismatch between forms and contextual markers. Therefore, it's inappropriate.

The difference of thanking reflects the difference of politeness that Chinese culture stresses the maxim of modesty whereas English culture highlights the maxim of approbation. Thus the lack of authentic contextual knowledge results in pragmatic failure.

\subsection{Dynamic Compensation}

Wang's compensation hypothesis is obvious to view the compensation in language use synchronically and statically. It displays a single track process and therefore is somewhat limited since it is confined just within the role of L1 contextual knowledge compensating the lack of the authentic context compatible with L2 use, without consideration of L2 knowledge's role. According to this paper, if a diachronic and dynamic perspective is adopted, it is found that L2 contextual knowledge also comes in and plays such a role in promoting compensation to vary from quantity to quality as the L2 learners' interlanguage system develops.

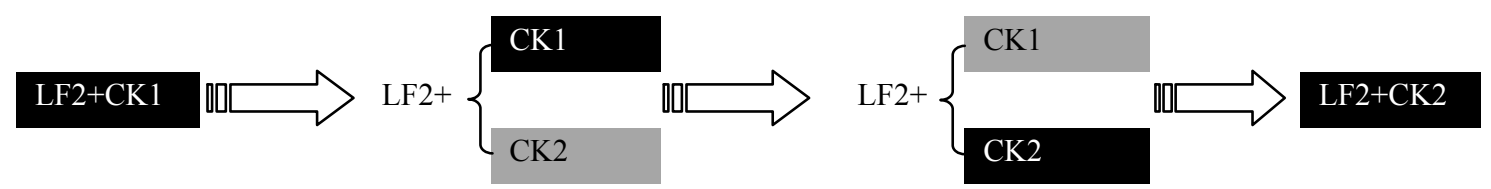

LF2: L2 form; CK1: L1 contextual knowledge; CK2: L2 contextual knowledge

Figure 1. Dynamic compensation of contextual knowledge

As the figure displays, an ideal L2 learner will go through four stages of knowledge reconstruction encompassing the match between L2 form, contextual knowledge and authentic context, from a new learner till the native-like speaker. For example, at the initial stage of EFL learning, compensation for the lack of the authentic context automatically depends on L1 contextual knowledge because L2 knowledge is very limited, then partially on L1 contextual knowledge as L2 contextual knowledge gradually accumulates and comes into 
the compensation, next strategically on L2 contextual knowledge when interlanguage system is well built, and finally automatically on L2 contextual knowledge. In fact, not more than 5 percent of L2 learners can ultimately reach the final stage, namely proficiency of native speakers according to current study. Most of them primarily experience the first two or three stages of development. Therefore, compensation is unavoidable esp. for L2 learners in foreign language environment.

Compensation is not static and mono-directional in the process of L2 learning. Development of L2 proficiency will gradually change the role of L1 contextual knowledge, esp. for the advanced EFL learners whose L2 contextual knowledge is perhaps far more than L1 contextual knowledge. But owing to the restriction of classroom setting, there might appear a dilemma that as their sense of context grows, L2 learners have to make a choice between linguistic forms activated by both L1 and L2 contextual knowledge when they come into compensation for the lack of the authentic context knitted with L2 use. Under this circumstance, L2 learners have to depend on their own contextual cognition to make a proper match between context, contextual knowledge and L2 forms to guarantee the accuracy and appropriacy of language use in a specific communicative situation. Therefore, dynamic compensation necessarily promotes cognitive processing in the choice-making of linguistic and strategic forms.

\section{Contextual Cognition and Thanking}

Language use is context-dependant. In the context of foreign language learning, L2 contextual knowledge plays a critical part in compensating the lack of authentic context with L2 use, because it guarantees the match between linguistic form and function in a given context and makes appropriate language use possible. But a language user needs to manipulate his contextual cognition consciously to bridge between contextual knowledge and authentic context in cross-cultural communication since the former as abstraction of the latter is stored in memory through classroom learning after all. By contextual cognition is meant a language user's ability of relating utterances to context by recognizing, constructing and analyzing the relevant contextual parameters to have an accurate understanding of explicit and implicit utterance meaning, and meanwhile make different choices of linguistic forms and strategies according to different communicative context so as to use language appropriately and express himself well. On the contrary, failure in contextual cognition tends to result in language users' inappropriate response whether they make no verbal choice or they make a wrong choice of L2 forms.

2) A: who's the artist?

B: The painter's not too well known. He's a modern London painter named ...

A: (puzzled) I was wondering if someone in the family was an artist.

In the example above, $\mathrm{A}$ is an American painter and B is an English woman living in America, who was showing the painter around her house before the painter's working. When the painter saw the oil painting on the wall, he said, "Who's the artist?" Quite clearly, B failed in contextual cognition because she interpreted A's utterance as a real question instead of a compliment. In fact, this is a typical American compliment in that situation, very much like the functions of Who's the cook? Who's the gardener? when someone's cooking or gardening is flattered. In that situation, people are very inclined to show their gratitude by saying It's a hobby, thank you or I'm just a fan, thanks. Thus contextual cognition determines language users' interpretation of utterances and proper linguistic response toward them.

\section{Adaptation of Thanking to Dynamic Context}

As L2 contextual knowledge comes into compensation, a language user has to rely on his contextual cognition to make linguistic and strategic choices of thanking, whereby expressing appreciation adequately and appropriately. In that process, the key to successful language use for an EFL learner consists in adaptation of his choice-making to dynamic context of thanking compatible with L2 use.

\subsection{Perspective of Adaptation}

As a polite speech act frequently used in daily communication, thanking is a pragmatic phenomenon. Pragmatics, according to Verschueren's adaptation theory $(2000$, p. 7$)$, is specified as "a general cognitive, social and cultural perspective on linguistic phenomena in relation to their usage in form of behavior." He points out "using language must consist of the continuous making of linguistic choices, consciously or unconsciously, for language-internal (structural) and/or language -external reasons. These choices can be situated "at any level of linguistic form" (pp. 55-56) as well as strategies. Human's making of linguistic choices derives from the specific properties that language itself has, namely variability, negotiability and adaptability, with which humans can use language in a dynamic way. Of the three properties, adaptability refers to "the property of language which 
enables human beings to make negotiable linguistic choices from a variable range of possibilities in such a way as to approach points of satisfaction for communicative needs" (p. 59) and apparently, it entails variability and negotiability simultaneously. It includes contextual correlates of adaptability, structural objects of adaptability, dynamics of adaptability and salience of the adaptation process respectively. In short, the study of pragmatic phenomena as dynamic processes operating on context-structure relationships at various levels of salience is simply to understand the meaningful functioning of language, i.e. to trace the dynamic generation of meaning in language use.

Under the guidance of the adaptation theory, appropriacy of the speech act of thanking can be understood as adaptability; that is to say, appropriate use of the speech act of thanking is a dynamic and adaptation-driven process, in which a speaker makes linguistic and strategic choices of the speech act of thanking to adapt himself to the hearer's mental world, social world and physical world for his realistic and potential benefit from the hearer, whereby promoting a successful communication as well as establishing or maintaining harmonious interpersonal relationship.

\subsection{Making Choices}

\subsubsection{Linguistic and Strategic Forms of Thanking}

As to linguistic forms, expressions of thanking are variable, ranging from simple and phatic utterances to lengthy and communicative events, with explicit or implicit gratitude lexical devices, as Example 3) displays below. Some are neutral, some formal, others informal. Choice of thanking expressions also changes as times marches on. Some becomes popular, some out of date. For example, most of Britons nowadays say cheers, or just smile to show their appreciations according to a survey. Four out of ten said that Thank you sounded too formal, so they used more catchy, chatty words such as fab, lovely or wicked.

3) Thanks; Many thanks; Thanks a lot; Thanks a million.

Thank you; Thank you very much.

How can I thank all of you?

I really don't know how to thank you.

How nice of you to do that!

I am grateful to you for your kindness.

It's very kind of you to come to meet us.

I enjoyed every minute that I spent here.

I greatly appreciated your timely help.

Cheers; Brilliant; Lovely; Fab; Awesome; Wicked; Merci; Ace

That's great; All right; Much appreciated; You star; Nice one

In terms of strategies, the speech act of thanking may be verbal or non-verbal, direct or indirect, and always open-ended. Aijmer (1996, p. 37) initiated the following figure to show the kinds of strategies people usually employ to express their gratitude in English.

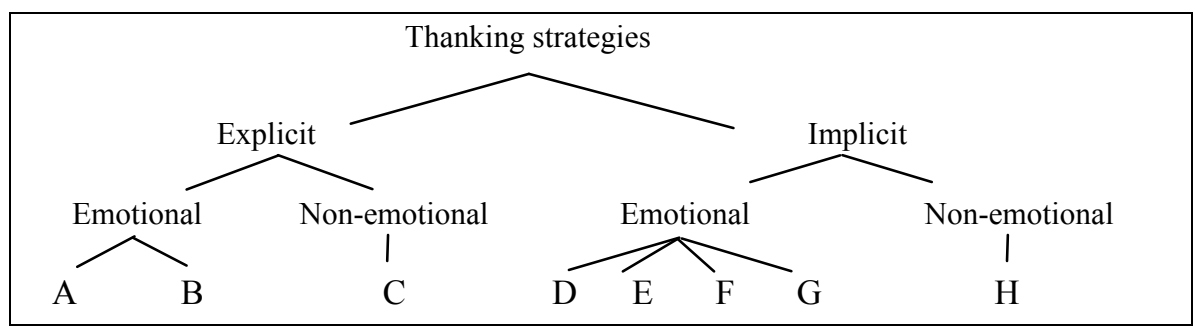




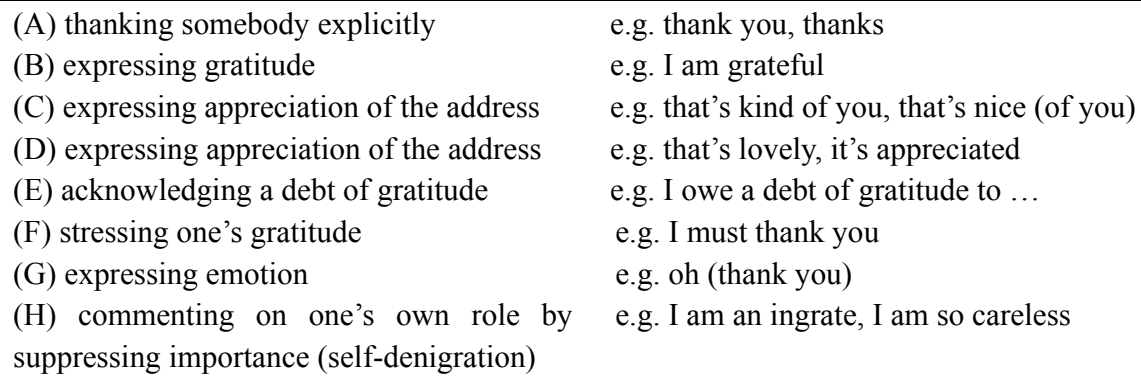

Figure 2. Description of Aijmer's strategies of expressing gratitude

Liu (2004) put forward another four strategies based on Aijmer's study so as to explain the thanking strategies employed by Chinese, like I (positive opinion), J (compliment, promise, and reward in the future), K (apology) and L (showing care). These are the full embodiment of thanking in Chinese culture. Simple transfer of these strategies into English is doomed to pragmatic failure.

\subsubsection{Paralinguistic Strategies}

When thanks are given, paralinguistic strategies are conceived of as important parameters to promote linguistic expressions, such as gestures, facial expression and physical appearance. According to Qian (2002, p. 110), these factors, called a bunch of accompanying signs, can participate verbal communication on behalf of linguistic sign, passing on their sign meanings into speech through their visible and audible image, so they are universally considered speaking louder than words in communication. For instance, according to the poll of 3,000 people carried out by the online gift store Me to You, 77 percent said that any of the words used to say thanks were irrelevant, believing a pleasant gesture works just as well. One third said they would often just resort to a quick wave instead of saying 'thank you'. Spokesman Caroline Weaver said, "Everyone knows that a big smile and some form of acknowledgment is all it takes to show we are grateful."

\subsection{Adaptation to the Dynamic Context}

Context is dynamic. Since language use is context-dependant, a language user has to manipulate his contextual cognition so as to make proper linguistic or paralinguistic choices for successful communication. In the process of thanking, such three important contextual parameters are particularly taken into consideration as the object of gratitude, the benefactor's psychological state, and the social world.

\subsubsection{Adaptation to the Object of Gratitude}

Object of gratitude, according to Coulmas (1981), refers to some action (or action) of a benefactor or to a result of this action which arouses every verbalization of thanking or every sincere verbalization of thanking. Thanking or expressing gratitude tends to be originated just from these realistic or potential benefits a beneficiary does or will gain. The benefit may be material like a gift, a service, or immaterial like a well-wish, a compliment. Therefore, to be appropriate in using the speech act of thanking, a beneficiary has to make appropriate choices to adapt to different objects of gratitude first, which motivates the thanking behavior and determines the degree of thanking. Usually, short and simple linguistic choices of thanking adapts to small services, favors or help, etc. For example Thanks or Thank you is used routinely when a person is handed a cup of coffee or a cigarette, offered all types of information like names, telephone numbers, the way to the station, inquired about his health, or given a compliment in English, as follows.

4) A: Another drink?

B: Yeah. Thanks.

5) A: Here is your ticket, sir.

B: Thanks.

6) A: Feel free to give me a call, if you have a question.

B: I appreciate it very much.

7) A: Enjoy yourself. Have a nice time.

B: Thank you, bye.
A: Bye 
The ritual phrases of thanking above are good manifestation of phatic communion of language, not only between friends and acquaintances but between strangers. The linguistic and strategic choices that the beneficiaries make adapt appropriately to the benefit they gain. But they are not common in Chinese culture; otherwise it appears that the beneficiaries are too polite to appropriate. Chinese-speaking learners of English are used to observing Chinese convention to make no thanking response in those cross-cultural communicative situations. On the other hand, Thank you modified with special intensifiers or expanded into a long and complicated one, like Thank you very much indeed, thank you a thousand times, or thanks a million, is not adaptive to the routine communication but to some big favors and help as in urgent need or in danger.

8) A: How is he, John?

B: He's asleep. He's going to be fine. How can I thank all of you?

A: Thank my son Bob. He pulled him out of the water.

B: I'm very grateful, Bob.

C: Dad saved him, not me.

B: I'm so grateful to all of you.

A: So long.

In conversation 8), the linguistic forms of thanking are relatively lengthy and complicated, full of strong emotion and well adaptive to the great benefit of life-saving. The first is How can I thank all of you which expresses Speaker A's inability by means of an interrogative sentential form. The second and the third have a similar sentence structure I'm grateful modified by lexical intensifiers very and so respectively, both frequently used in formal situations expressing a speaker's truly felt gratitude. Generally speaking, when the object of gratitude weights far over what a beneficiary expects, he usually expresses his profound gratitude by making such negative or interrogative linguistic choices as I can't tell you how much I appreciate this; I can't tell you what this means to me; I don't know what I should have done without your help; how can I thank you enough. Therefore, the inability to express gratitude highlights the value of the benefaction and represents a strong feeling of thanking in roundabout way, while the simple and short form only adapts to the routine benefit. In a word, linguistic choice of forms adaptive to different objects of gratitude is appropriate and acceptable.

\subsubsection{Adaptation to Psychological State of the Benefactor}

Thanking belongs to expressive speech acts, expressing speaker's psychological state toward a state of affairs or a person (Searle, 2001a, p. 65). This is speaker's mental world, according to Verschueren (2000), who notes that verbal interaction is communication from mind to mind; "mind" here refers to "mind in society" (p. 87). A beneficiary expresses gratitude to his benefactor by making appropriate linguistic choices of thanking, according to him, is the dynamic process to realize adaptation between their minds. The mind may be individual as well as societal. Individual psychology is concerned with communicator's personality traits, emotional involvement, patterns of beliefs, wishes and desires, motivation and intentions, while societal psychology with the universal psychological state shared by all the members in a speech community, like the psychological imprint of culture and social system. In intra-language communication in which societal psychology has been shared, adaptation to the individual psychology is firstly taken into consideration. Comparatively, in inter-language communication in which different societal psychology clashes first, priority is definitely put on adaptation to it. Thus, the more dynamically adaptive to the different psychological state, the more appropriate the linguistic choices of thanking in its use.

9) Erin Brockovich: Thank you.

The postman: Thank you.

The above conversation took place while Erin Brockovich signed her name on the document and gave it back to the postman who handed over a package to her in 1996 Oscar-winner Erin Brockovich. This example is, to a large extent, strange to Chinese-speaking learners of English who are familiar with the situation that they would say You are welcome, My pleasure or That's Ok as a response to Thank you. In fact, the interlocutors in the conversation thank each other with different motivations. Erin Brockovich thanks the postman for his bringing the parcel to her, while the postman thanked Erin Brockovich for her signing on the document, which is indicative of his fulfillment of his work. In this situation, both Erin Brockovich and the postman are beneficiaries as well as benefactors. Choice of Thank you as a simple linguistic form adapts well to the mutual psychological states in a service; therefore they are used adequately and appropriately. 
10) A: Well, that was delicious! Thanks very much indeed. I know that you are a really good cook.

B: Thank you. Would you like something to drink? A cup of coffee?

A: No, thank you. It's too late. I really have to go.

B: Would you like to call home?

A: I'd appreciate that.

B: Please, use the phone.

\section{A: Thanks. Excuse me.}

Thanking is performed five times in this short conversation above. All of them are appropriate because they adapt to the benefactor's kindness or hospitality, and even refusing with the expression No, thank you sounds soft, polite and acceptable. However, Chinese tend to say jut No without thank you attached. It fully demonstrates the high frequent use of such a ritual convention in daily English communication even in polite refusing. However, thanking in the example is absolutely considered too polite to be appropriate and acceptable in Chinese culture especially between friends and acquaintances so that the host or hostess will very possibly blame the speaker thinly for their formal speech acts.

11) A: Excuse me, could you tell me the way to Zhejiang Museum?

B: I'm sorry. I don't know.

A: Thank you all the same.

In Example 11), the linguistic form of Thank you all the same as a response is adaptive well to the dynamic communication even though the foreigner failed to acquire the information.

Thanking in the three examples above is usually unfamiliar to the Chinese-speaking learners of English, so that they generally don't show their gratitude in those communicative situations in Chinese culture. Therefore, thanking is very likely to be neglected in cross-cultural communication and then pragmatic failure is brought about. Actually, psychology of expressing gratitude is cross-culturally different event though it is a universal ritual. According to Qu \& Chen (2001), indirect speech act of thanking is used more frequently instead of the direct ones among Chinese because it is believed that insiders like family members, relatives, friends and acquaintances are not necessarily that polite to each other. The indirect thanking is dynamic, varying from context to context based on the degree of intimacy between a benefactor and a beneficiary, while the direct thanking is ritual, often attached with "Xiexie" mainly for a benefactor who really does a great favor to a beneficiary $(\mathrm{Bi}, 2009)$. That is in keeping with traditional Chinese politeness principle, in which intimacy of relation and relative power between interlocutors play a critical role in determining the choice of linguistic forms. Unlike that, direct speech act of thanking is used rather frequently in English culture; it is said the phatic phrase of Thank you is used even thousands of times by English people everyday even between parents and children, wives and husbands since thanksgiving and equality is culturally deep-rooted. It is these trivial disparities that make Chinese EFL learners need pay special attention to adaptation to the societal psychology and avoidance of the simple transfer of thanking in cross-cultural communication.

\subsubsection{Adaptation to the Social World}

Social world in Adaptation Theory mainly refers to social settings (or institution), principles and norms. Adaptation to the social world means that communicators' speech acts are restricted or governed by social and cultural norms, which usually determines the formality of communication, the illocutionary force and the functions of language. From time to time, hosts or conductors put an end to TV programs or journey by performing the speech act of thanking, whereas audiences or passengers have no such illocutionary force and functions. In English culture, the typical thanking situation includes greeting and saying goodbye to the guests, receiving invitations, presents, wishes and help, etc. Use of thanking has no restriction in those situations regardless of age gap, social relation, social status and benefits between communicators. Use of speech acts is appropriate as long as the linguistic choices of them adapt to the dynamic communicative situation; for example, Thank you for your coming, Thank you for the visit, Thank you for your presence, Thank you for your gift, Thank you for your help (time, advice, etc.). The choice of for phrase above demonstrates the dynamic adaptation.

In addition, there exist other highly idiomatic situations of thanking. For example, in closing a telephone call, ending the questions in debate, accepting the proposal and refusing an offer, the speech act of thanking will be used, mainly for turn of conversation. The priority is naturally put on the textual functions of thanking instead of its emotive function and phatic communion. 
12) (Situation: this is a debate about fox-hunting)

A: I give it to you. Will you sign it?

B: No.

A: Thank you. Will you sign it, Mr. Danby?

C: No.

A: Thank you. My question is answered.

(Coulmas, 1981, p. 87)

13) (Situation: the conductor hands over a ticket)

Conductor: Thank you.

Passenger: Thank you.

Conductor: Thank you.

(Coulmas, 1981, p. 91)

In these communicative situations above, the linguistic choices of thanking are simple in form. The key to its appropriate use consists in adaptation to the turn of conversation and textual cohesion. On the contrary, the lack of its use tends to make the conversational turn incomplete and thus, inappropriateness arises.

All of the above are the barriers for Chinese EFL learners who are unfamiliar with that culture. In addition, with the deep influence of Chinese traditional culture like "Never Forget the kindness after benefited", "abundant repayment for the even little kindness", Han people have a different interpretation of objects of gratitude from Anglo-American people. Furthermore, owing to the deep-rooted concept of relation standard in Han culture, use of thanking differs between communicators with a concern of social distance, age gap, intimacy degrees and relative power. And also owing to the influence of cultural convention like "denigration of oneself and respect to others", Han people tend to make indirect linguistic choices of thanking such as apology-making type, concern-showing type and promise-making type to express their thankfulness and appreciation to the benefactors. It is on account of the cultural distinction that makes simple transfer of thanking speech act give rise to pragmatic failure in cross-cultural communication so that Chinese EFL learners make no response or respond in Chinglish, and thus inappropriateness arises. In short, it is crucial for a beneficiary to have a dynamic adaptation to the social communicative situation in expressing thankfulness or appreciation.

\section{Conclusion}

So far this essay has explored how to make the speech act of thanking appropriate and acceptable in cross-cultural use for Chinese EFL learners, who tend to use mute English or Chinglish in many thanking situations, which results in pragmatic failure. Thanking as a convivial speech act is polite inherently. Its appropriate use is therefore the paramount consideration. From the perspective of foreign language development, the essay investigates the dynamic compensation when L2 contextual knowledge comes gradually into L2 learning process. With this change, guided by contextual knowledge, a language user has to make flexible choices from the possible language resources of thanking and try to adapt those choices to such dynamic context compatible with L2 use as objects of gratitude, psychological state of the benefactor and the social context, thereby promoting an appropriate use of thanking and finally achieving a communicative need of expressing appreciation. Of the three contextual parameters, adaptation to objects of gratitude is the starting point, adaptation to psychological state of the benefactor is the central consideration and adaptation to social context is the macro-background. In a word, abundant contextual knowledge with L2 use makes contextual cognition powerful and adaptation flexible, and finally appropriate use of language is possible.

\section{Acknowledgements}

I would like to thank Jianping Li for her helpful feedback on an earlier version of this paper and Xiaorong Zheng for helping with the collection of the data and first proof-reading. I also like to thank the three anonymous reviewers for their insightful comments and suggestions.

\section{References}

Ahar, V., \& Eslami, A. (2011). The Effect of Social Status and Size of Imposition on the Gratitude Strategies of Persian and English Speakers. Journal of Language Teaching and Research, 2(1), 120-128. http://dx.doi.org/10.4304/j1tr.2.1.120-128

Aijmer, K. (1996). Conversational Routines in English: Convention and Creativity. London: Longman. 
Austin, J. L. (2002). How to Do Things with Words. Beijing, China: Foreign Language Teaching and Research Press \& Macmillan Publishers Ltd.

Bi, J. W. (2009). Intercultural Communication and Second Language Teaching (pp. 38-40). Beijing, China: Beijing Language University Press.

Brown, P., \& Levinson S. (2002). Politeness: Some Universals in Language Usage. Cambridge: Cambridge University Press.

Cheng, W. J. (2005). An exploratory cross-sectional study of interlanguage pragmatic development of expressions of gratitude by Chinese learners of English. Retrieved February 27, 2013, from http://ir.uiowa.edu/etd/104

Coulmas, F. (1981). Poison to your soul: thanks and apologies contrastively viewed. In Coulmas, F. (Ed.), Conversational Routine. The Hague: Mouton.

Cui, X. B. (2012). A Cross-linguistic Study on Expressions of Gratitude by Native and Non-native English Speakers. Journal of Language Teaching and Research, 3(4), 753-760. http://dx.doi.org/10.4304/j1tr.3.4.753-760

Du, X. Z. (2010). Comparison of Cultures and Conventions between China and English Countries. Beijing, China: Foreign Language Teaching and Research Press.

Eisenstein, M., \& Bodman J. W. (1986). I Very Appreciate: Expressions of Gratitude by Native and Non-native Speaker of American English. Applied Linguistics, 7, 167-185. http://dx.doi.org/10.1093/applin/7.2.167

Farnia, M., \& Suleiman, R. (2009). An Interlanguage Pragmatic Study of Expressions of Gratitude by Iranian EFL Learners - A Pilot Study. Malaysian Journal Of ELT Research, 5, 108-140.

Hee, S. P., \& Lee, H. E. (2012). Cultural Differences in "Thank You". Journal of Language and Social Psychology, 3(2), 138-156. http://dx.doi.org/10.1177/0261927X12438536

Hou, G. J. (2004). Dynamic politeness-appropriateness interaction. Us-China Foreign Language, 2, 26-36.

Johansen, S. H. (2008). A comparative study of Gratitude Expressions in Norwegian and English from An Interlanguage Pragmatic and Second Language Acquisition Research Perspective. Retrieved February 27, 2013, from https://www.duo.uio.no/handle/123456789/25531

Leech, G. (1983). Principles of Pragmatics. London: Longman.

Liu, W. S. (2004). Comparison of English and Chinese Gratitude Expressions and Chinese EFL Learners' Pragmatic Transfer of Gratitude Expressions. Journal of Nantong Vocational University, 1, 97-100.

Most of Britons Say "cheers", "ta" or Just Smile to Show Appreciation, Retrieved February 27, 2013, from http://www.chinadaily.com.cn/language_tips/news/2010-08/25/content_11199260.htm

Pishghadam R., \& Zarei, S. (2011). Expressions of Gratitude: A Case of EFL Learners. Review of European Studies, 3(2), 140-149. http://dx.doi.org/10.5539/res.v3n2p140

Qian, G. L. (2002). Pragmatics on Chinese Culture. Beijing, China: Tsinghua University Press.

Qu, W. G., \& Chen L. F. (2001). The Study of Indirect Speech Act of Thanking in Shanghai Dialect. TCSOL Studies, (3), 69-78.

Searle, J. R. (2001a). Expression and Meaning: Studies in the Theory of Speech Acts. Beijing, China: Foreign Language Teaching and Research Press \& Cambridge University Press.

Searle, J. R. (2001b). Speech Acts: an Essay in the Philosophy of Language. Beijing, China: Foreign Language Teaching and Research Press \& Cambridge University Press.

Verschueren, J. (2000). Understanding Pragmatics. Beijing, China: Foreign Language Teaching and Research Press \& Edward Arnold (Publishers) Limited.

Wang, C. M. (2003). Compensation Hypothesis and Foreign Language Learning. Foreign Language Research, 1 , $1-5$.

Wolfson, N. (1989). Perspectives: sociolinguistics and TESOL. New York: Newbury House Publisher.

\section{Author}

Baiqiu Liao (1976-), a male lecturer of Leshan Normal University, with academic interest in applied linguistics and pragmatics. 